\title{
Clinical and genetic characteristics of two cases with Williams-Beuren syndrome
}

\author{
Liu-Xu Wang, Jie Leng, Zhong-Hui Li, Li Yan, Peng Gou, Fang Tang, Na Su, Chun-Zhu Gong, \\ Xin-Ran Cheng \\ Department of Pediatric Endocrine Genetics and Metabolism, Chengdu Women's and Children's Center Hospital, School of Medicine, University \\ of Electronic Science and Technology of China, Chengdu, China \\ Correspondence to: Xin-Ran Cheng. Department of Pediatric Endocrine Genetics and Metabolism, Chengdu Women's and Children's Center Hospital, \\ School of Medicine, University of Electronic Science and Technology of China, Chengdu 610091, China. Email: cxr1216@sina.com.
}

\begin{abstract}
Herein, we describe 2 cases of Williams-Beuren syndrome (WBS). In both cases, the patients exhibited mental retardation, characteristic facial features, and indirect inguinal hernia. Case 1, a girl aged 2 years and 5 months old, presented with hypercalcemia, and in case 2, a boy aged 4 years and 11 months old, the disorder manifested as infantile spasms, supravalvular aortic stenosis, and pulmonary stenosis. Brain MRI revealed no abnormalities in either case. The electroencephalogram of case 2 showed hypsarrhythmia. Case 1 was treated with bisphosphonates and somatropin for hypercalcemia and short stature. Case 2 received antiepileptic drug and ketogenic diet therapy. In both cases, a 7q11.23 deletion including fragment deletion of the GTF21 gene was found, which may be associated with mental retardation. Notably, in case 2, a $921.1 \mathrm{~kb}$ deletion in Yq11.23 was detected, which has not been reported in WBS before. The deletion of Yq11.23 is located in the AZFc region, which is an important factor in male infertility with primary azoospermia and oligozoospermia. The occurrence of hypercalcemia in case 1 may be related to the deletion of $B A Z 1 B$, while the supravalvular aortic stenosis and pulmonary stenosis were associated with deletion of the ELN gene. We explored the clinical and genetic characteristics of WBS to better understand disease.
\end{abstract}

Keywords: Williams-Beuren syndrome (WBS); gene; mental retardation; infantile spasms; hypercalcemia, case report

Submitted Feb 26, 2021. Accepted for publication Jun 01, 2021.

doi: $10.21037 / \mathrm{tp}-21-161$

View this article at: http://dx.doi.org/10.21037/tp-21-161

\section{Introduction}

Williams-Beuren syndrome (WBS) is a rare multisystem developmental disease caused by a heterozygous deletion of 1.5 to $1.8 \mathrm{Mb}$ on $7 \mathrm{q} 11.23$ (1). The syndrome was first described in 1961 and 1962 by Dr. Williams and Dr. Beuren, respectively, who reported cases of supravalvular aortic stenosis accompanied by characteristic facial features. This syndrome has an incidence of 1 in 7,500 to 1 in 20,000 live births (2). In 1993, genetic research identified the cause of WBS as being chromosome deletion of 7 q11.23 ranging from 1.5 to $1.8 \mathrm{Mbp}$ and containing 26 to 28 genes. The mechanism of the gene deletions which lead to different clinical manifestations has remained unclear. The absence of heterozygosity in a series of adjacent genes located on the long arm of chromosome 7 is believed to be the genetic cause of WBS (3).

WBS is mainly characterized by unique facial features, cardiovascular anomalies, intelligence retardation, infantile hypercalcemia, and distinctive behavior. Here, we will analyze the clinical manifestations, personal history, supplementary examination, and chromosome detection results of 2 cases with WBS. We present the following article in accordance with the CARE reporting checklist (available at http://dx.doi.org/10.21037/tp-21-161). 


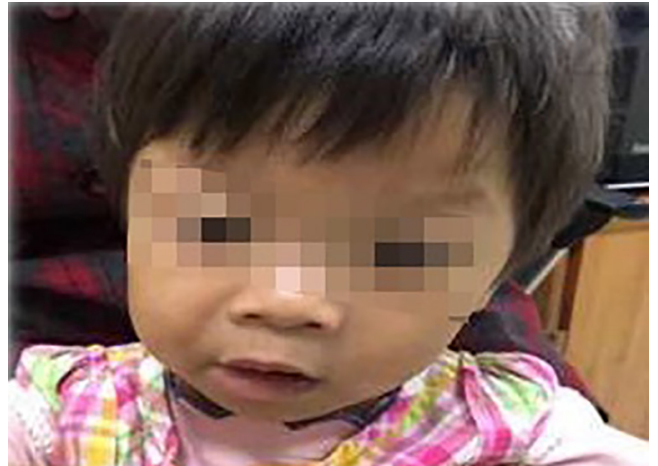

Figure 1 Case 1, a female, aged 2 years and 5 months, has characteristic facial features.

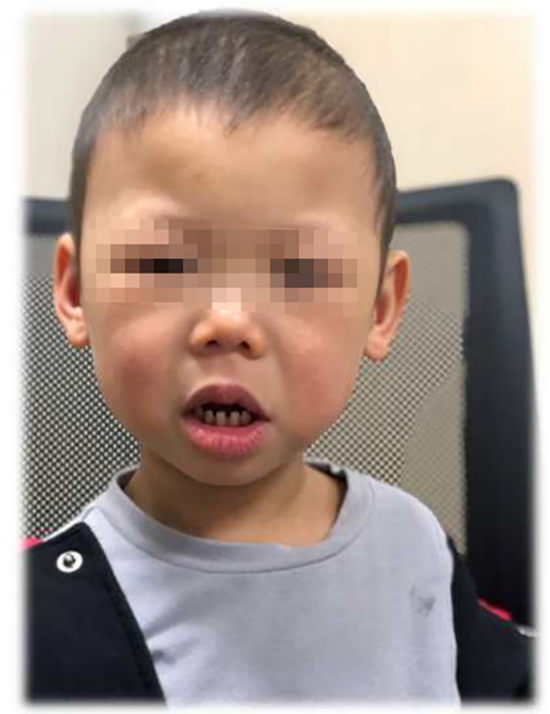

Figure 2 Case 2, a male, aged 4 years and 11 months, has characteristic facial features.

\section{Case presentation}

All procedures performed in studies involving human participants were in accordance with the ethical standards of the institutional and/or national research committee(s) and with the Helsinki Declaration (as revised in 2013). Written informed consent was obtained from the patient.

\section{Case 1}

A female aged 2 years and 5 months old visited hospital after experiencing mental retardation for 2 years and hypercalcemia for 10 months (Figure 1). The patient had been born at a gestational age of 37 weeks with a body weight of $1,700 \mathrm{~g}$, as the $2^{\text {nd }}$ child of healthy parents. During the pregnancy, her mother had been diagnosed with diabetes. The patient's 11-year-old brother had a history of epilepsy and attention deficit syndrome. At the age of 1 year and 8 months, the patient had presented at hospital with severe malnutrition, hypercalcemia, and abnormal liver function. Due to her short stature, the patient had received growth hormone therapy in Beijing Hospital when she was 2 years and 4 months old. During the past year, the patient had recurrent hypercalcemia, which had once been treated with calcium bisphosphonate.

Physical examination revealed coarse facial features with full orbital, a spherical nose, a flat nasal bridge, a long philtrum, and thick lips. The cranial MRI, electroencephalogram, and echocardiography results were normal. Abdominal ultrasonography revealed right oblique inguinal hernia. The deletion of chromosomal band 7q11.23 was found by fluorescence in situ hybridization analysis, thus confirming WBS.

\section{Case 2}

A boy aged 4 years and 11 months old, the $1^{\text {st }}$ child of healthy parents, visited hospital having experienced mental retardation and convulsions for 2 years (Figure 2). He had been born at a gestational age of 39 weeks, weighing 2,500 g.

Physical examination showed classical facial characteristics, such as full orbital, a spherical nose, a flat nasal bridge, a long philtrum, thick lips, a wide mouth, and irregular teeth. The brain MRI results were normal. The electroencephalogram revealed hypsarrhythmia. Abdominal ultrasonography also showed oblique inguinal hernia. The patient had supravalvular aortic stenosis, pulmonary stenosis, infantile spasm, and facial features fitting with WBS. Chromosome microarray analysis revealed a 1,500-kb deletion on 7 q11.23 and a $921.1 \mathrm{~kb}$ deletion on Yq11.23.

The patient was treated in West China Hospital of Sichuan University and Peking University First Hospital on October 2016. He was given adrenocorticotropic hormone therapy for 14 days, followed by prednisone for 2 months, which was gradually stopped. He was also given levetiracetam, sodium valproate, topiramate, and a ketogenic diet. However, the use of sodium valproate was stopped due to abnormal liver function, and the patient showed intolerance to the ketogenic diet. On April 2019, the patient experienced global tonic seizures and was subsequently treated with lamotrigine. No more seizures 
were reported in the half month prior to the writing of this case study.

\section{Discussion}

WBS was first described as a triad of distinctive facial features, supravalvular aortic stenosis, and mental retardation (4). The 2 cases described above had characteristic facial features, mental retardation, and oblique inguinal hernia. One study has considered whether cardiovascular defects and connective tissue disorders (such as oblique inguinal hernia) in WBS result from either microdeletions or point mutations of the $E L N$ gene (5). Furthermore, the GTF2I gene has been related to social communication and social anxiety in WBS (6), and deficiency of GTF2I has negative effects on neurocognition and behavior.

WBS is a multisystem developmental disease caused by a 1.55 to $1.83 \mathrm{Mb}$ deletion at $7 \mathrm{q} 11.23$ including 26 to 28 genes. The mechanism of WBS is the rearrangement of low copy repeats within or between chromosome 7 q11.23 region. Most patients with Williams syndrome have breakpoints in chromosomal regions that occur within duplicates $(7,8)$. About $5 \%$ of patients have atypical deletions. Atypical deletions in Williams-Beuren syndrome patients often have severe cognitive retardation and seizures, including infantile spasms. There have some research revealed that the gene contained in the atypical deletion is the basis of infantile spasms in children with Williams syndrome $(9,10)$.

Patients with WBS present with a variety of endocrine dysfunctions, such as postnatal growth retardation, precocious puberty, hypothyroidism, diabetes, thyroid disorders, and idiopathic hypercalcemia. If children with Williams-Beuren syndrome have endocrine abnormalities, a low-calcium diet, insulin, thyroxine, growth hormone or GnRH will be given when necessary (11). Approximately $15 \%$ of patients with WBS present with transient hypercalcemia, while $5 \%$ of patients may have severe conditions with renal medullary calcinosis (12). The $B A Z 1 B$ gene has been observed to cause hypercalcemia in animal models (13); thus, the hypercalcemia described in case 1 may be related to the deletion of $B A Z 1 B$. Severe hypercalcemia may lead to adverse manifestations, which makes the early identification of hypercalcemia in patients especially important.

Approximately $70 \%$ of patients with WBS have supravalvular aortic stenosis. Other cardiovascular defects include aortic stenosis and pulmonary artery stenosis, ventricular or atrial septal defects, and myxomatous degeneration of aortic or mitral valve leaflets (14). Studies have shown that abnormal production of elastin in patients with WBS usually results in overgrowth of smooth muscle, which can cause vascular lesions in medium and large arteries. Haploinsufficiency of the ELN gene can cause cardiovascular anomalies. Neurological manifestations of WBS may be associated with a distal 7q11.23 deletion $(15,16)$. Koch et al.'s research suggested that the MAGI2 gene may be involved in infantile spasm (17). In WBS cases, atypical deletion of WBSCR involving the HIP1 and $Y W H A G$ genes may result in a tendency toward the neurophenotype (18).

The patient in case 2 was found to harbor a $921.1 \mathrm{~kb}$ deletion on Yq11.23, which has not been reported in WBS before. This deletion was located in the $A Z F_{c}$ region, which contains 3 OMIM genes: DAZ1,DAZ2, and DAZ3. AZF microdeletion is an important factor in male infertility with primary azoospermia and oligozoospermia (19). Foresta et al.'s research revealed that Y chromosome longarm microdeletions were found in $6 \%$ of infertile men and most frequently involved the $A Z F c$ region (20). $D A Z$ genes encode an RNA-binding protein which plays an important role in spermatogenesis (21). The male patient in this study has no abnormal external genitalia at present, but his sexual characteristics and hormonal changes will be monitored during follow-up.

The 2 cases described above had characteristic facial features, mental retardation, and oblique inguinal hernia. Patients with WBS should be regularly monitored for progressive vascular and stenosis through growth and development, blood pressure, and auditory, visual and cardiovascular evaluations. In clinical practice, if there are special abnormal findings, the focus should be on screening for atypical heart malformation. The rare cases we have described of deletions of the Yq11.23 region associated with WBS suggest the need for further investigations.

\section{Acknowledgments}

Funding: This work was supported by Sichuan Science and Technology Program (grant No. 2019JDPT0034).

\section{Footnote}

Reporting Checklist: The authors have completed the CARE reporting checklist. Available at http://dx.doi.org/10.21037/ tp-21-161 
Conflicts of Interest: All authors have completed the ICMJE uniform disclosure form (available at http://dx.doi. org/10.21037/tp-21-161). The authors have no conflicts of interest to declare.

Etbical Statement: The authors are accountable for all aspects of the work in ensuring that questions related to the accuracy or integrity of any part of the work are appropriately investigated and resolved. All procedures performed in studies involving human participants were in accordance with the ethical standards of the institutional and/or national research committee(s) and with the Helsinki Declaration (as revised in 2013). Written informed consent was obtained from the patient.

Open Access Statement: This is an Open Access article distributed in accordance with the Creative Commons Attribution-NonCommercial-NoDerivs 4.0 International License (CC BY-NC-ND 4.0), which permits the noncommercial replication and distribution of the article with the strict proviso that no changes or edits are made and the original work is properly cited (including links to both the formal publication through the relevant DOI and the license). See: https://creativecommons.org/licenses/by-nc-nd/4.0/.

\section{References}

1. Pober BR. MEDICAL PROGRESS Williams-Beuren Syndrome (vol 362, pg 239, 2010). N Engl J Med 2010;362:2142.

2. Ji C, Yao D, Chen W, et al. Adaptive behavior in Chinese children with Williams syndrome. BMC Pediatr 2014;14:90.

3. Merla G, Ucla C, Guipponi M, et al. Identification of additional transcripts in the Williams-Beuren syndrome critical region. Hum Genet 2002;110:429-38.

4. Beuren AJ, Schulze C, Eberle P, et al. The syndrome of supravalvular aortic stenosis, peripheral pulmonary stenosis, mental retardation and similar facial appearance. Am J Cardiol 1964;13:471-83.

5. Merla G, Brunetti-Pierri N, Piccolo P, et al. Supravalvular aortic stenosis: elastin arteriopathy. Circ Cardiovasc Genet 2012;5:692-6.

6. Crespi BJ, Hurd PL. Cognitive-behavioral phenotypes of Williams syndrome are associated with genetic variation in the GTF2I gene, in a healthy population. BMC Neurosci 2014;15:127.

7. Pérez Jurado AL. Williams-Beuren syndrome: a model of recurrent genomic mutation. Horm Res 2003;59 Suppl 1:106-13.

8. Del Campo M, Antonell A, Magano LF, et al. Hemizygosity at the NCF1 gene in patients with WilliamsBeuren syndrome decreases their risk of hypertension. Am J Hum Genet 2006;78:533-42.

9. Nicita F, Garone G, Spalice A, et al. Epilepsy is a possible feature in Williams-Beuren syndrome patients harboring typical deletions of the 7q11.23 critical region. Am J Med Genet A 2016;170A:148-55.

10. Samanta D. Infantile spasms in Williams-Beuren syndrome with typical deletions of the 7q11.23 critical region and a review of the literature. Acta Neurol Belg 2017;117:359-62.

11. Kim YM, Cho JH, Kang E, et al. Endocrine dysfunctions in children with Williams-Beuren syndrome. Ann Pediatr Endocrinol Metab 2016;21:15-20.

12. Palacios-Verdú MG, Segura-Puimedon M, Borralleras C, et al. Metabolic abnormalities in Williams-Beuren syndrome. J Med Genet 2015;52:248-55.

13. Pober BR. Williams-Beuren syndrome. N Engl J Med 2010;362:239-52.

14. Collins RT 2nd. Cardiovascular disease in Williams syndrome. Circulation 2013;127:2125-34.

15. Ramocki MB, Bartnik M, Szafranski P, et al. Recurrent distal 7q11.23 deletion including HIP1 and YWHAG identified in patients with intellectual disabilities, epilepsy, and neurobehavioral problems. Am J Hum Genet 2010;87:857-65.

16. Nicita F, Garone G, Spalice A, et al. Epilepsy is a possible feature in Williams-Beuren syndrome patients harboring typical deletions of the 7q11.23 critical region. Am J Med Genet A 2016;170A:148-55.

17. Koch K, Marshall C, Young E, et al. Infantile Spasms in Individuals with Williams-Beuren Syndrome are Associated with Deletion of the MAG12 Gene on Chromosome 7q11.23-7q21.11. Front Hum Neurosci 2009;3. doi: 10.3389/conf.neuro.09.2009.07.058 .

18. Fusco C, Micale L, Augello B, et al. Smaller and larger deletions of the Williams Beuren syndrome region implicate genes involved in mild facial phenotype, epilepsy and autistic traits. Eur J Hum Genet 2014;22:64-70.

19. Vogt PH. Human chromosome deletions in Yq11, AZF candidate genes and male infertility: history and update. Mol Hum Reprod 1998;4:739-44.

20. Foresta C, Garolla A, Bartoloni L, et al. Genetic abnormalities among severely oligospermic men who are 
candidates for intracytoplasmic sperm injection. J Clin Endocrinol Metab 2005;90:152-6.

21. Tsui S, Dai T, Roettger S, et al. Identification of two novel proteins that interact with germ-cell-specific

Cite this article as: Wang LX, Leng J, Li ZH, Yan L, Gou P, Tang F, Su N, Gong CZ, Cheng XR. Clinical and genetic characteristics of two cases with Williams-Beuren syndrome. Transl Pediatr 2021;10(6):1743-1747. doi: 10.21037/ tp-21-161
RNA-binding proteins DAZ and DAZL1. Genomics 2000;65:266-73.

(English Language Editor: J. Reynolds) 